\title{
Dirsek çevresi cerrahi yaklaşımlar
}

\author{
Surgical approaches around the elbow
}

\author{
Taner Güneş, Erkal Bilgiç \\ Gaziosmanpaşa Üniversitesi Tıp Fakültesi, Ortopedi ve Travmatoloji Anabilim Dalı, Tokat
}

Dirsek bölgesine uygulanacak cerrahi yaklaşımlar, dirseğin kompleks anatomisi nedeni ile özelliklidir. Dirsek çevresindeki vasküler ve nörolojik yapıların çokluğu yanında, dirsek ekleminin stabilitesini sağlayan yapılar nedeniyle cerrahi yaklaşımlar kompleks olabilir. ilgili patolojinin cerrahi tedavisinin en başarılı şekilde yapılması, uygun bir cerrahi yaklaşımın seçilmesine bağlıdır. Dirsek çevresine cerrahi müdahalelerde, mediyal, lateral, anterior, posterior ve bir de bunların kombinasyonları şeklinde tanımlanmış yaklaşımlar mevcuttur. Hangi yaklaşımın hangi patoloji için kullanılabileceğinin bilinmesi temel kuraldır.

Anahtar sözcükler: cerrahi tedavi; dirsek
Surgical approaches of the elbow region have specific features due to the complex anatomy of the elbow. Accordingly, these approaches may also be complex due to the structures providing elbow stability in addition to vascular and neurological structures of the region. Successful management of the related pathology around the elbow joint is closely related to the selection of suitable surgical approach. The surgical approaches around the elbow joint are classified as medial, lateral, anterior, posterior, and combinations of these. Knowing which approach is the best for related pathology is the basic rule for appropriate treatment.

Key words: operative therapy; elbow
$\mathrm{D}$ irsek bölgesindeki damar, sinir ve ligamentöz yapıların fazlalığı dirsek çevresi cerrahi yaklaşımlarını kompleks hale getirir. ${ }^{[1]} \mathrm{Bu}$ nedenle cerrahi anatominin çok iyi bilinmesi en temel kuraldır. Dirsek eklemi çevresinde mediyal, lateral, posterior ve anterior yaklaşımlar ile cerrahi işlemler gerçekleştirilebilir. Her bir yaklaşım tedavi edilecek patolojiye göre seçilmelidir. Aynı tedavi için farklı cerrahi yaklaşımlar kullanılabilir. Burada her bir yaklaşımın avantaj ve dezavantajları göz önünde tutularak seçim yapılması gereklidir. Ayrıca, cerrahi yaklaşım seçiminde aşağıdaki ölçütler göz önünde bulundurulmalıdır; ${ }^{[2]}$

1. Öngörülemeyen durumlar için uzatılabilir olmalıdır.

2. Problemi çözebilmek için gerekli tam bir görüntüleme kapasitesi olmalıdır.

3. İşlem sırasında vital yapıların görüntülenmesi ve korunmasını sağlayacak şekilde güvenli olmalıdır.

4. Cerrahi işlem sırasında tüm anatomik yapıları mümkün olduğunca koruyabilmelidir.
5. Kas, tendon ve bağların içinden geçmek yerine bu yapıların aralarındaki planlardan ilerlemeye izin vermelidir.

6. Geniş cerrahi yaklaşımlarda sıkı kanama kontrolü yapılmalıdır.

7. Dikkatli cerrahi kapamaya özen gösterilmelidir.

\section{HASTA POZISYONU VE CILT INSIZYONLARI}

Rutin olarak supin pozisyonda skapula altını destekleyerek, daha sonra humerus proksimaline ulaşmak gerektiğinde çıkılabilmesi için, steril turnike kullanılması önerilmektedir. Bu pozisyonun avantajları, anestezi ekibinin kolay çalışması, skopi kullanım kolaylığı, iliak kanattan greft alınmasının kolaylığıdır. Dezavantajı ise kolu tutmak üzere asistan gerekliliğidir. Ameliyat masası karşı tarafa doğru döndürülerek görüntü arttırılabilir. Bu pozisyon distal humerus ve radius başı kırık tespiti ve mediyal ve lateral-kollateral bağ işlemleri için en uygun olanıdır. Skopi aynı taraftan kullanılır. Supin pozisyonu ayrıca mediyal kollateral bağ işlemleri

- Illetişim adresi: Prof. Dr. Taner Güneş, Gaziosmanpaşa Üniversitesi Tıp Fakültesi, Ortopedi ve Travmatoloji Anabilim Dalı, Tokat Tel: 356 - 2129500 / 1282 e-posta: drtgunes@gmail.com

- Geliștarihi: 10 Ocak2014 Kabul tarihi:10 Ocak2014 
yanında, koronoid kırıkları içinde uygundur. Hastanın yan yatırılmasının avantajı, dirseğin posterioruna asistan gerekmeden kolayca ulaşılabilmesidir. Ancak, skopi kullanımı zordur.

Dirsekte en fazla kullanılan insizyon evrensel posterior insizyondur. Bu insizyon mediyal ve lateral tam kat cilt flepleri sayesinde dirseğin çevresel olarak bir çok bölgesine erişilebilmesine imkan tanır. Ayrıca tek bir insizyon ile cilt köprüleri meydana getirilmesine gerek kalmadan birçok bölgeye ulaşılabilir. Diğer bir avantajı ise, mediyal ve lateral insizyonların aksine çok az sayıda küçük cilt sinirini çaprazlamasıdır. Bu nedenle, semptomatik kutanöz sinir yaralanması (parestezi, ağrılı nöroma, nörit) görülme riski daha azdır. Potansiyel problemi, büyük mediyal ve lateral flepler altında meydana gelen büyük boşluk nedeni ile hematom ve seroma oluşma riskidir. Alternatif olarak mediyal ve lateral insizyonlar kullanılabilir. Eğer eski operasyonlara ait cilt insizyon skarları varsa bu insizyonlar çaprazlanmamalı ve arada dar cilt köprüleri oluşturulmamalıdır. Aksi takdirde bu köprülerde nekroz gelişebilir.

\section{POSTERIOR YAKLAŞIMLAR}

Endikasyonları:

- Distal humerus ve olekranon kırıkları

- Triseps tendon işlemleri

- Total dirsek artroplastisi (TDA)

Kemik çıkıntı noktaları işaretlenir. Olekranon superiorundan, trisepsin ortasından insizyonlara başlanır. Olekranon seviyesinde lateral veya mediyalden dönülerek distale doğru uzatılır. Lateral veya mediyalden dönülmesi cerrahın tercihine bağlıdır. Mediyal ve lateral tam kat cilt flepleri yaratılır. Bu fleplerin mümkün olduğunca kalın olması önemlidir. Ulnar sinir mediyal intermusküler septum proksimalinde kolaylıkla bulunur. Ulnar sinirin ekleme giden dalları kesilebilir. Fleksör karpi ulnarise (FKU) giden motor dal korunmalıdır. FKU'nun derin ve yüzeyel fasyası gevşetilir. Eğer ulnar sinir anteriora transfer edilecekse intermusküler septumun eksize edilmesi gereklidir. Daha sonra sinir mediyal epikondil üzerinde anteriora yerleştirilir. Transfer sonrası, sinirin yeni yerinde kolay hareket edebildiğinden emin olunmalıdır. Eğer transfer edilmeyecek ise, sinirin kübital tünel içerisindeki stabilitesinin bozulmaması için, Osborne fasyasının bozulmaması gereklidir. Bazı yazarlar kırık tespiti ve total dirsek artroplastisi için transfer, sert dirsek tedavisi için ise dekompresyon önermektedirler. ${ }^{[1]}$ Posterior insizyonlarda önemli diğer bir konu dirseğin posterioruna ulaşmak için trisepsin yönetilmesidir.

Triseps yönetimi:

- Olekranon osteotomisi

- Triseps sıyırma (Bryan-Morrey, TRAP)

- Triseps ayırma

\section{- Paratrisipital}

Distal humerus eklem yüzünün olekranon osteotomisi ile \%57'sinin görünmesi mümkün olurken, bu oran triseps-ayırma ile \%35 ve triseps sıyırma ile \%46 olarak ölçülmüştür. ${ }^{[3]}$ Olekranon osteotomisi dışındaki tekniklerde trisepsin hangi bölgesinden ayrılacağı Şekil 1'de gösterilmiştir.

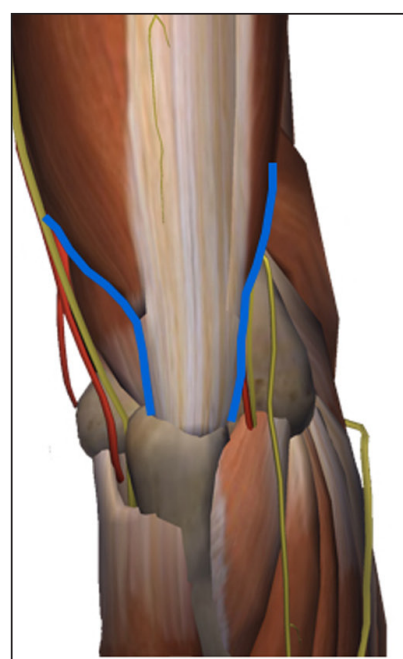

Paratrisipital

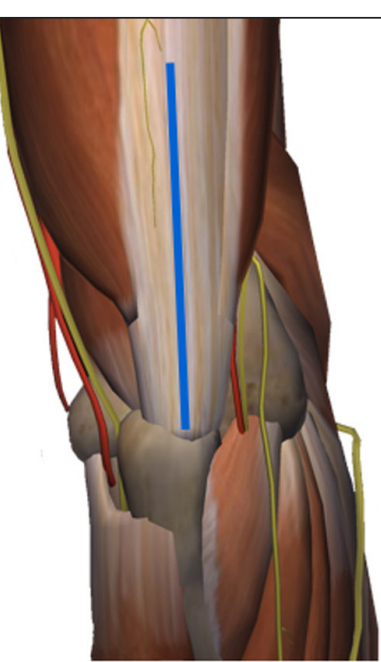

Ayırma

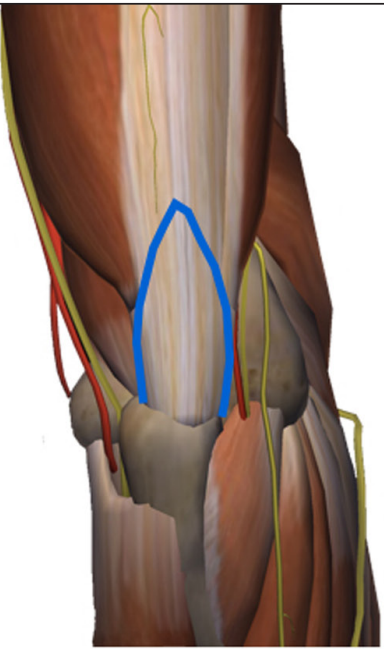

Van Gorder

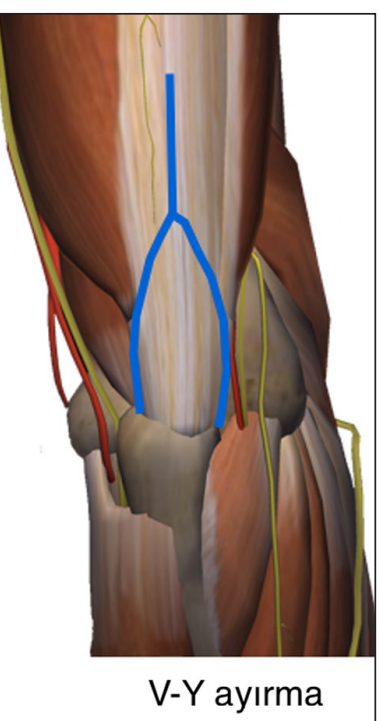

V-Y ayırma

Şekil 1. Posterior yaklaşımda olekranon osteotomisi dışındaki diğer triseps yönetim metodları. 


\section{Olekranon osteotomisi}

Olekranon osteotomisi (OO) humerus eklem içi kırıklarının tedavisi için eklem içinin en uygun şekilde görülebilmesini sağlar. Bu açıdan cerrahi yaklaşımların en iyisidir. Dezavantajları: kaynamama riski ve eklem içi yapışıklıktır; ayrıca, tespit için kullanılan tespit materyalleri cilt irritasyonu yapabilirler; sementli ulnar komponent kullanılan total dirsek protezi için uygun değildir. Ulnar sinir eksplorasyonu sonrasında büyük sigmoid çentiğin ortasına kadar eklem mediyal ve lateralden açılır (Şekil 2a). Standart teknikte ankoneus kasının innervasyonu bozulabilir. Ankoneusun inervasyonu bu bölgedeki radyal sinirin terminal dalları ile sağlanır. Bu dalları korumak için Mayo modifikasyonu kullanılır. ${ }^{[4]}$ Bu teknikte, ankoneus olekranon osteotomize parçası ile devamlılığı kalacak şekilde kaldırılır. Bunun için ankoneus kasının osteotomi bölgesine kadar distali ulnadan ayrıştırılır. Proksimal olekranon fragman ile birlikte ankoneus kası proksimale doğru kaldırılır. Osteotomi için farklı yöntemler olmasına rağmen genellikle Chevron tipi (apeksi distalde olacak şekilde) osteotomi kullanılır. Osteotomiye posterior kortekste motorlu testere ile başlanır. Eklem yüzünde osteotom kullanılır (Şekil 2b). Bu aşamada eklem yüzünde küçük çıkıntıların olması tespit sırasında tam redüksiyon ve stabilizasyon için yararlıdır (Şekil 2c). Osteotomi tamamlandıktan sonra trisepsin mediyal ve lateral kenarları tamamen açılarak distal humerus tamamen ortaya konur (Şekil 2d). Osteotomi genellikle sorunsuz iyileşir ve problem genellikle tespit yöntemine bağlıdır. ${ }^{[5]}$ Eğer
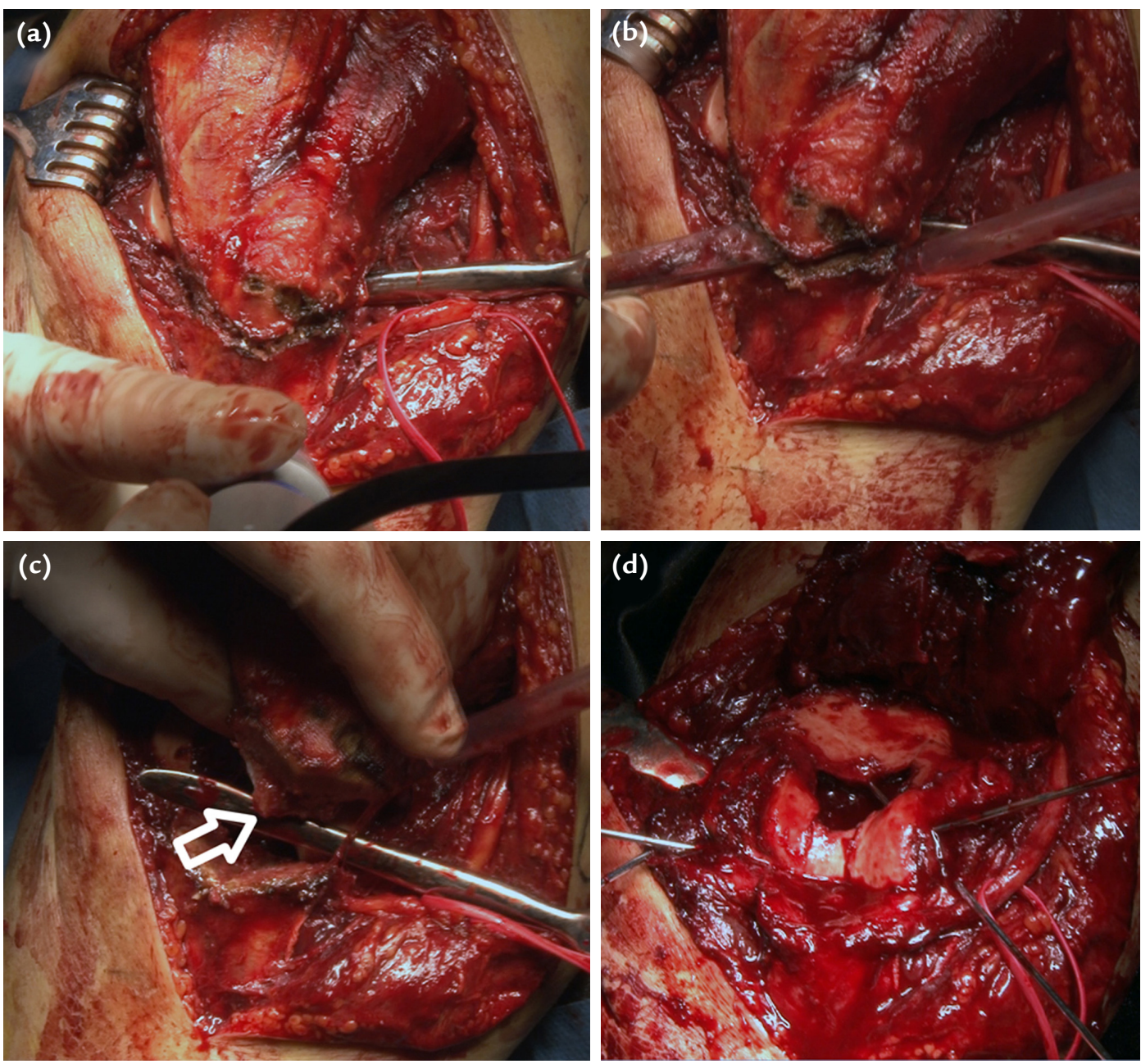

Şekil 2. a-d. Olekranon osteotomisi basamakları. Trisepsin mediyal ve lateral kenarlarından ulno-humeral eklem açılır (a). "V" şeklindeki osteotomiye önce motorlu testere ile başlanır, eklem seviyesinde osteotom ile tamamlanır. Bu aşamada, eklem aralığına keskin olmayan bir periost elevatörü yerleştirilmesiyle, eklem yüzü osteotomdan korunmuş olur (b). Eklem yüzünde kemik çıkıntı (içi boş ok) olması redüksiyona katkıda bulunur (c). Osteotomi tamamlandıktan sonra, trisepsin mediyal ve laterali proksimale doğru açılarak distal humerus görünür hale getirilir (d). 
tespit için vida kullanılacak ise osteotomi yapılmadan önce vidanın deliğinin hazırlanması tespiti kolaylaştırır. Eğer K-teli kullanılacaksa, koronoidin distalinde anterior kortekse dayanması önemlidir. Bunun için K-teli anterior kortekse dayandıktan sonra $5 \mathrm{~mm}$ kadar geri çekilir. Ucu $180^{\circ}$ bükülür ve yeniden çakılarak anterior kortekse dayanması sağlanır. Daha sonra triseps K-tellerinin bükülmüş olan uçlarının üzerine dikilir. Bu sayede tellerin geriye doğru gelmesi engellenmeye çalışılır. Bunun yerine, tespit için anatomik veya önceden bükülmüş plak da kullanılabilir.

\section{Triseps sıyırma}

Bryan-Morrey triseps sıyırma tekniği, triseps, ön kol fasyası ve periostun tek bir ünite şeklinde olekranondan mediyalden laterale sıyrılmasıdır. ${ }^{[6]}$ Ulnar sinir bulunur ve korunur. Bistüri yardımı ile triseps, ön kol fasyası ve periost olekranondan ayrilır. Bazen olekranondan ince bir kemik parça kaldırılır. ${ }^{[7]}$ Ekstansör mekanizma laterale sıyrılarak dirsek fleksiyona getirildiğinde distal humerus görünür hale gelir (Şekil 3). Ulnar sinirin laterale çekilmesi ve traksiyondan korunması gereklidir. TDA'da mediyal ve lateral bağlar kaldırılabilir. İşlemin sonrasında triseps ulnaya transosseöz sütürler ile dikilerek tamir edilir. Bu tamir altı hafta korunmalı ve aktif ekstansiyona izin verilmemelidir.

\section{Triseps slyırma ankoneus flebi (TRAP)}

TRAP tekniği, standart posterior yaklaşımdan daha uzun posterior insizyona ihtiyaç duyar. ${ }^{[8]}$ Ankoneus kası proksimal ulna lateralinde bulunarak subperiosteal olarak ulnadan ayrılır. Kas anüler ve lateral-kollateral bağlardan ayrılırken bu bağlar korunur. Diseksiyon proksimale, triseps kasının altına doğru ve suprakondiler bölgeye doğru ilerletilir. Ankoneus kası proksimal ulna ve distal kısmından tamamen ayrılabilir.

\section{Triseps ayırma}

Triseps ayırma distal humerus 1/3'ünde radyal sinire kadar sınırlı tutulmalıdır. Ulnar sinir korunmalıdır.
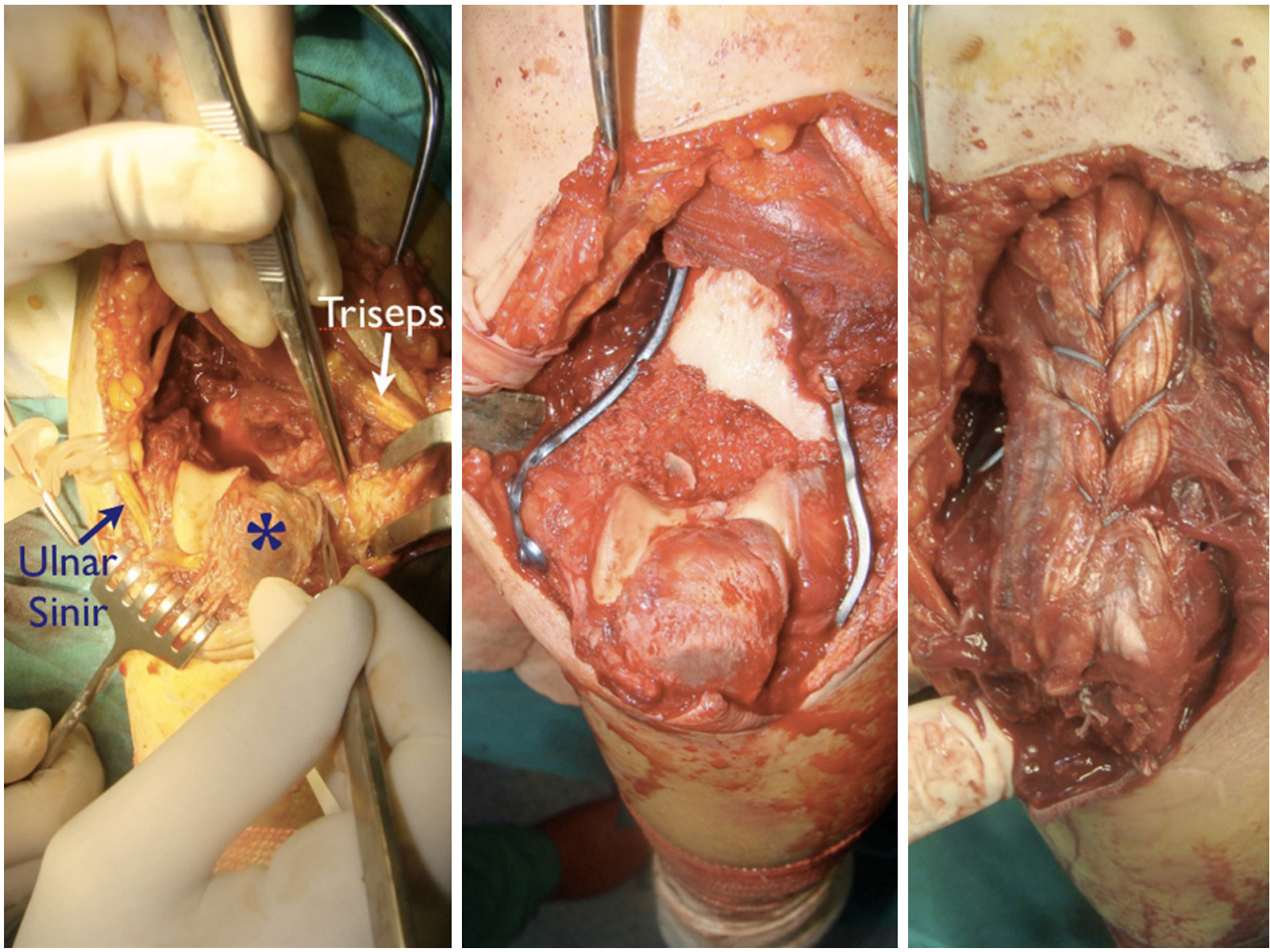

Şekil 3. Bryan-Morrey triseps sıyırma yaklaşımı. Triseps ameliyatın sonunda olekranona kalın emilmeyen sütürler ile tamir edilir (asterisk, olekranon). 

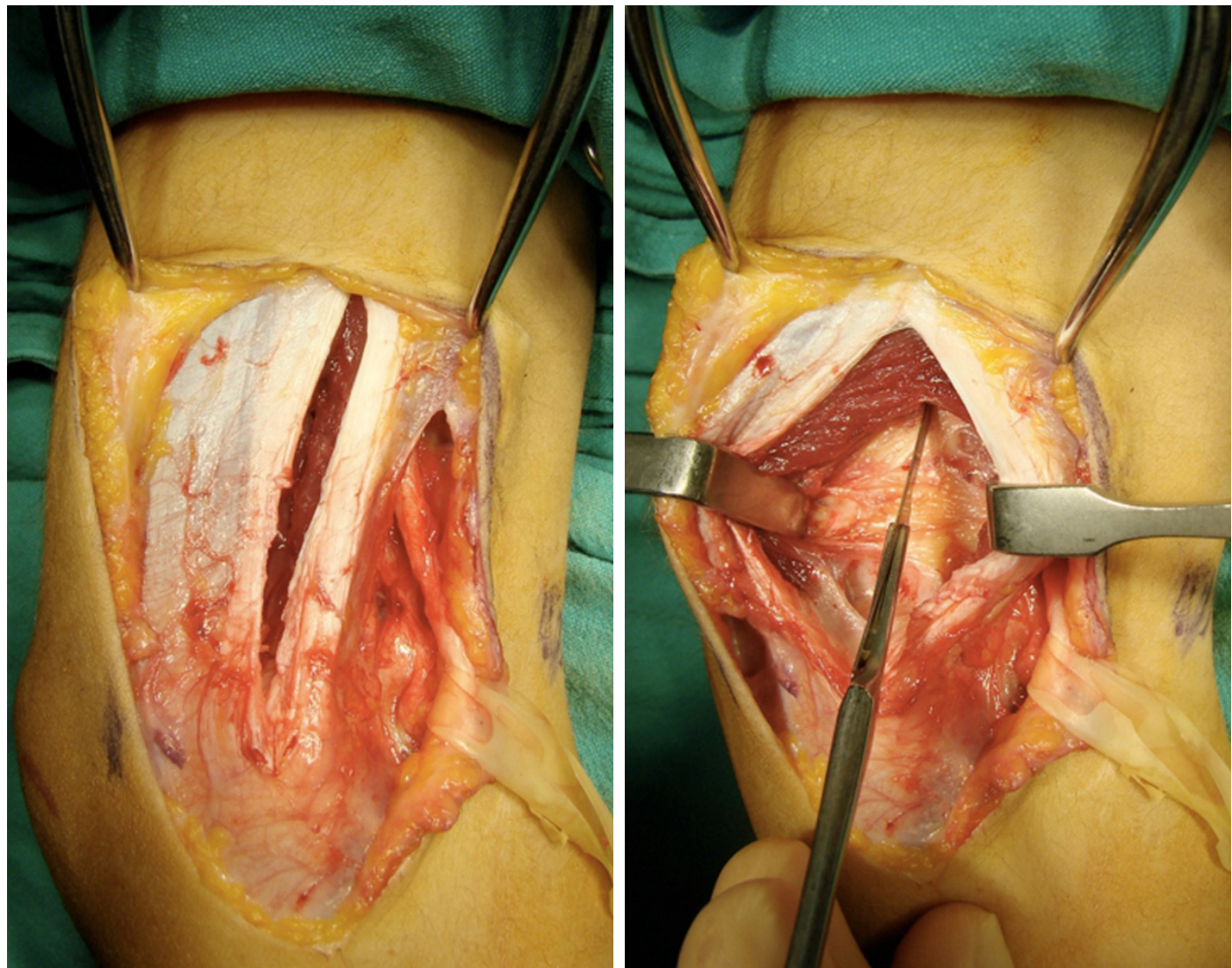

Şekil 4. Triseps ayırma tekniği. Proksimalde radyal sinirin trasesi düşünülerek, olekranona kadar triseps kesilir. Daha sonra periost ve eklem kapsülü açılır.

Radyal sinir düşünülerek triseps kas kısmından başlayarak olekranon tipine kadar ayırılır (Şekil 4). ${ }^{[9]}$ TDA için lateralde ankoneus kası subperiosteal kaldırılabilir. Van Gorder yaklaşımında ise, triseps tendon kas kısmından "V" veya "Y" şeklinde ayrılır.[10] "Y" şeklinde yapılması sert dirseklerde kasın uzatılmasını ve hareketin arttırılmasını sağlayabilir. Tamir sonrası altı hafta aktif dirsek ekstansiyonu yaptırılmamalıdır.

\section{Paratrisipital}

$\mathrm{Bu}$ yaklaşım Alonso-Llames tarafından geliştirilmiştir. ${ }^{[11]}$ Trisepsin insersiyosu sağlam kaldığından, ameliyat sonrasında triseps yetmezliği riski yoktur. Bu yaklaşım TDA planlanan yaşlı hastalardaki tamir edilmiş distal humerus kırıkları için idealdir. Ayrıca distal humerus kırık tespiti için de kullanılabilir. Trisepsin mediyal kenarı, mediyal intermusküler septum ile olekranon mediyalinden açılarak görünür hale getirilir. Lateralde ise triseps lateral intermusküler septumdan ve ankoneus kasından ayrılır (Şekil 5). İşlem sırasında triseps mediyal veya laterale alınabilir. Dirseğin ekstansiyona alınması ile görüntü arttırılabilir.

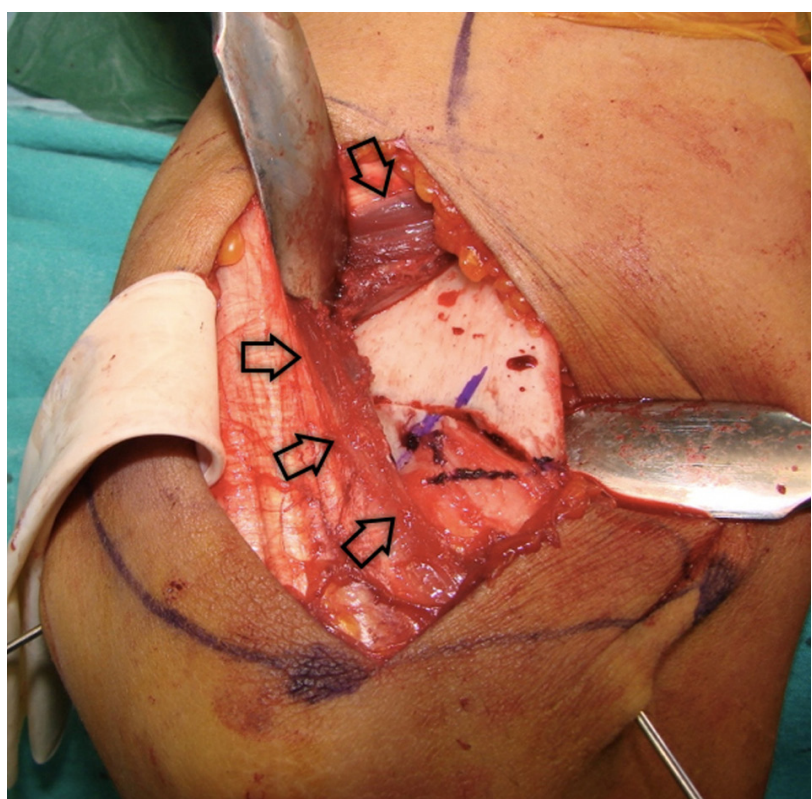

Şekil 5. Paratrisipital yaklaşım. Trisepsin mediyal ve laterali intermusküler septumlardan ayrılarak açılır ve humerus distali ve eklemin posterioruna ulaşılır (içi boş siyah oklar, triseps lateral kenarı). 


\section{MEDIYAL YAKLAŞIMLAR}

Mediyal yaklaşımlar sert dirsek tedavisi, kollateral bağ yaralanması ve kırık tespiti için kullanılır. Ayrıca koronoid kırıkları içinde kullanılabilir.

\section{Hotchkiss}

Mediyal gevşetme için uzunlamasına mediyal insizyon ile birlikte kullanılır. ${ }^{[12]}$ Güvenli bir cerrahi diseksiyon için ulnar sinirin ortaya konması ve korunması şarttır. Revizyon olgularında, ulnar sinirin transpoze olduğu durumlarda, daha proksimalden, normal alandan disseke edilerek distale ilerlemek ve ulnar siniri ortaya çıkarmak kullanışlıdır. Mediyal antebrakiyal sinir korunmalıdır; kesilmesi halinde ameliyat sonrası nöroma gelişebilir. Fleksör-pronator grup suprakondiler bölgeden ayrılır. Fleksör grup distale doğru longitudinal olarak ayrılır. Burada FKU posterior kısmının sağlam bırakılması önemlidir. Brakiyalis, FKU ve pronator teres anterior kapsülden ayrılır. Bu kasların ayrılması ile dirseğin lateraline ulaşmak mümkün olur. FKU'nun yanında mediyal kollateral bağın korunması önemlidir. Ayrıca brakiyal arter ve median sinir korunmalıdır.

\section{Kırık tespiti için mediyal koronoid yaklaşım}

Mediyal koronoid çıııntı kübital tünel tabanı boyunca ilerlendiğinde kolaylıkla ortaya konabilir. Posterior veya mediyal cilt insizyonu ile ulnar sinir bulunduktan sonra anteriora transpoze edilir veya kırık tespiti sırasında nazikçe posteriora doğru çekilir. Alternatif olarak fasyokutanöz askı içine alınarak işlem sırasında travma görmesi engellenir. FKU'nun iki başı ayrılır; anterior yarısı öne doğru alınır. Mediyal kollateral bağın anterior parçası genellikle büyük anteromediyal koronoid fragmanına bağlıdır. Bağın fragmana bağlantısının korunması gereklidir. FKU mediyal kollateral bağdan ayrılmalı ve proksimal orijini sağlam bırakılmalıdır. Koronoid fragman büyük ise, Taylor ve Scham'ın tarif ettiği gibi subperiosteal diseksiyon ile FKU anteriora alınır (Şekil 6). ${ }^{[13]}$

\section{ANTERIOR YAKLAŞIM}

Anteriordaki brakiyal arter ve median sinirin yaralanma ihtimali nedeniyle çok tercih edilen bir yaklaşım türü değildir; en çok bilineni Henry yaklaşımıdır. Bunun bazı modifikasyonları vardır. Selesnick ve arkadaşları tarafından ${ }^{[14]}$ tarif edilen yaklaşım, koronoid kırıklarının anterior yaklaşımla tespiti için önerilmektedir. ${ }^{[15]} \mathrm{Bu}$ yaklaşımda lateral proksimalden bağlayan ve mediyal distalde biten "S" şeklinde insizyon kullanılır (Şekil 7). Lasertus fibrozus, aponevrozun liflerine dik olarak kesilir. Diğer yüzeyel yapılar ekarte edilerek brakiyalis adalesine ulaşılır. Brakiyalis adalesi uzunlamasına açılarak anterior kapsül ve koronoid fragmana ulaşılabilir.

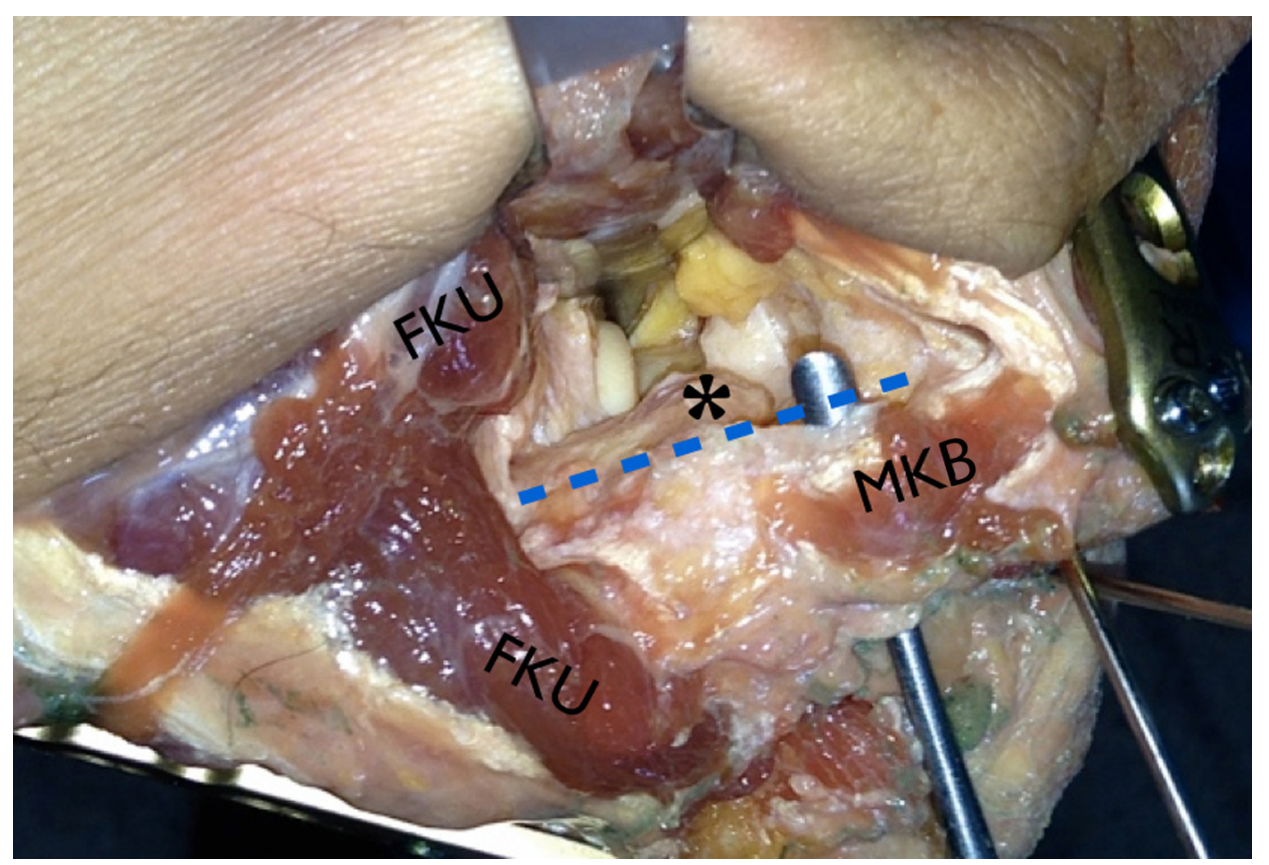

Şekil 6. Mediyal yaklaşım. FKU'nun iki başı arasından distalden başlanarak ulna anterior sınırı hizasından (mavi kesikli çizgi) başlanarak proksimale devam edilir ve eklem açılır. Bu sayede MKB'ye zarar verilmeden, eklemin mediyalinin ve koronoidin ortaya konması mümkün olur ( $F K U$; fleksör karpi ulnaris, $M K B$; mediyal kollateral bağ, asterisk, koronoid çıkıntı). 

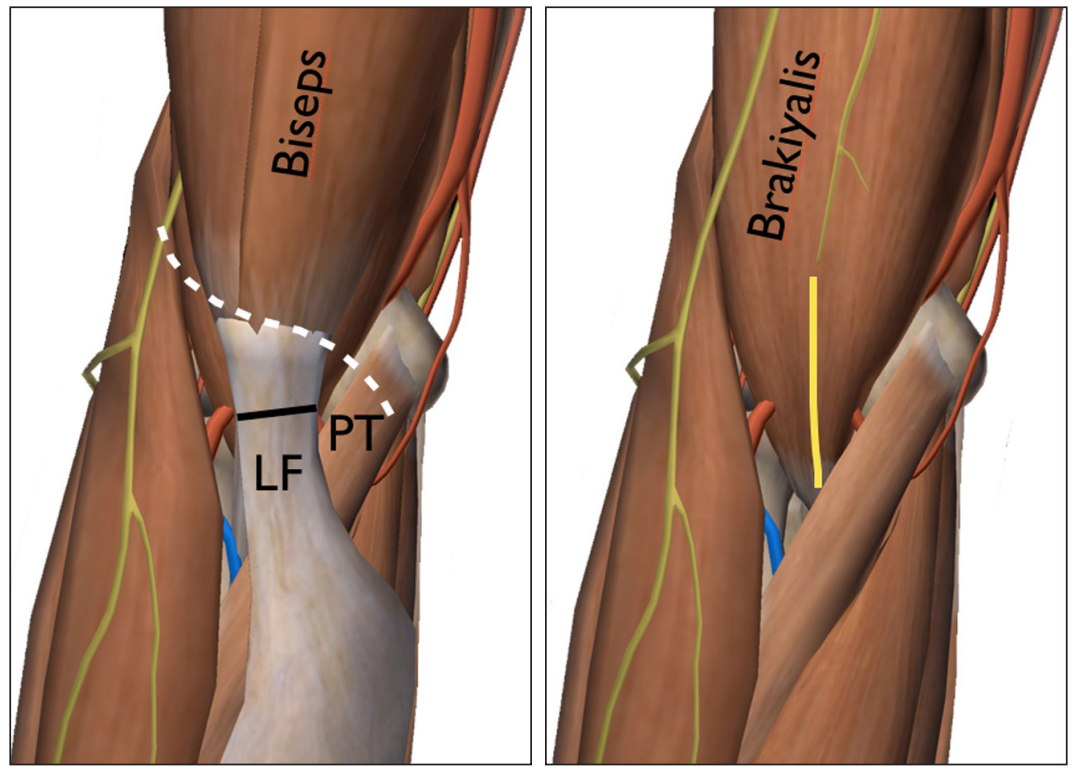

Şekil 7. Selesnick ve arkadaşlarının ${ }^{[14]}$ tanımladığı anterior yaklaşım. "S" şeklinde insizyon ile (kesikli beyaz çizgi) girilir. Lasertus fibrozis transvers kesilir (siyah çizgi). Brakiyalis adalesi derinde uzunlamasına açılır (sarı çizgi) ( $L F$, lasertus fibrozis; PT, pronator teres).

\section{LATERAL YAKLAŞIMLAR}

Dirseğin belki de en çok kullanılan cerrahi yaklaşımı lateral yaklaşımdır. Lateral bağ tamirleri, Monteggia, kapitellum, lateral kondil ve radius başı kırıklarının tedavisi için idealdir. Varyasyonları şunlardır: Kaplan, Kocher, lateral kolon, posterolateral. Bu yaklaşımlar arasındaki fark cilt insizyonunun yeri ve ekleme ulaşmak için kullanılan anatomik aralıklardır. Hangi yaklaşım kullanılırsa kullanılsın, posterior interosseöz sinir (PIS) ve radyal sinirin tekrarlayıcı dalı korunmalıdır.

\section{Kaplan lateral yaklaşım}

Lateral ulnar kollateral bağ (LUKB) kesilmeden radius başının mükemmel görüntülenmesini sağlar. Dirsek $90^{\circ}$ fleksiyonda lateral epikondilin üzerinden lister tüberkülüne doğru 3-4 cm'lik insizyon yapılır. Yüzeyelde ekstansör dijitorum kommunis (EDK) ile ekstansör karpi radyalis longus (EKRL) arasındaki intervalden girilir (Şekil 8). Derinde anüler ligament kesilir ancak radyokapitellar eklemin ekvatoru boyunca LUKB'nin anteriorunda kalınır. Bu yaklaşımda eğer fazla anteriorda kalınırsa posterior interosseöz sinir (PIS) yaralanabilir. PIS
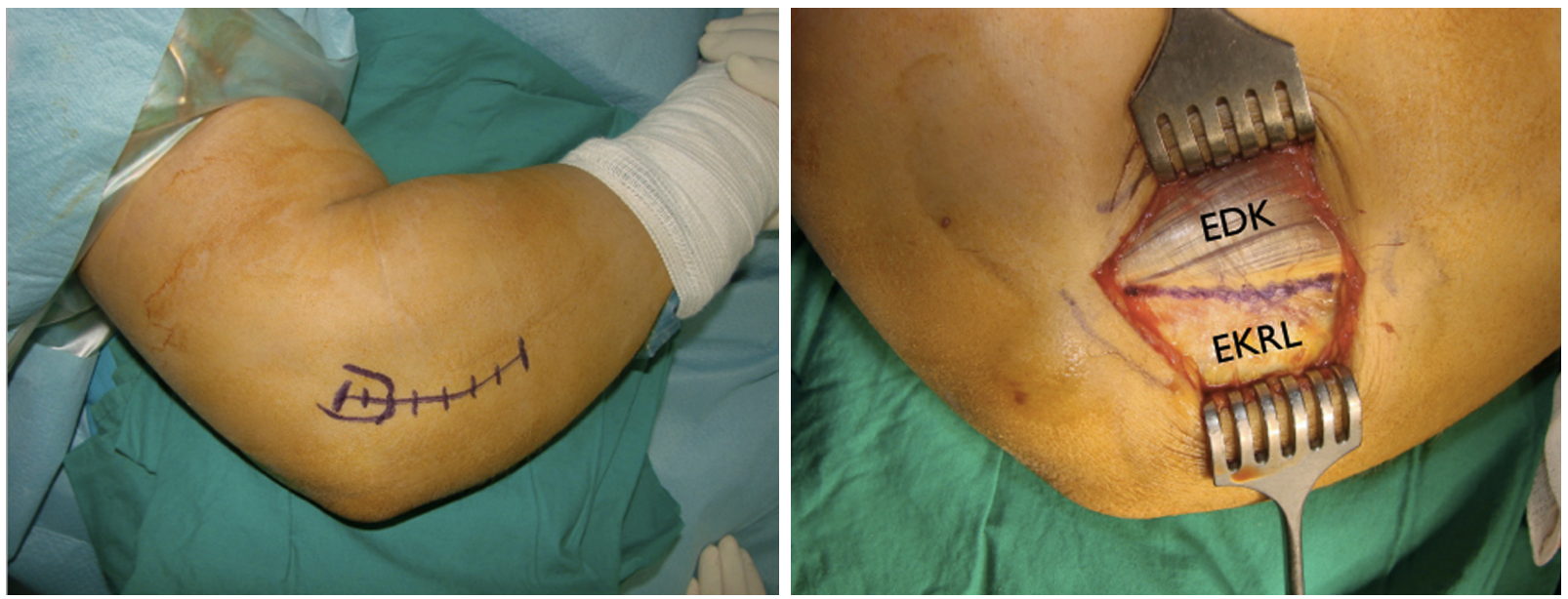

Şekil 8. Kaplan lateral yaklaşım ( $E D K$, ekstansör dijitorum kommunis; $E K R L$, ekstansör karpi radyalis longus). 

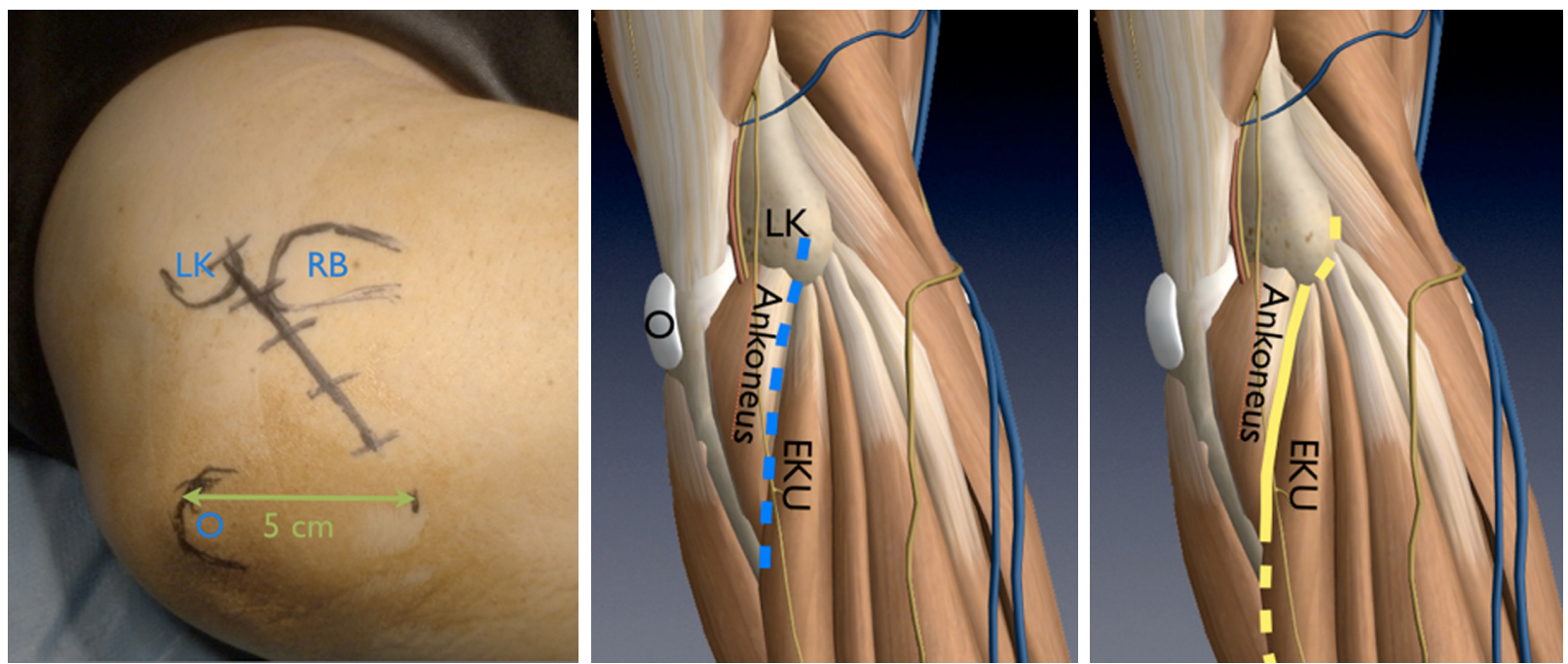

Şekil 9. Kocher lateral yaklaşım ( $L K$, lateral kondil; $R B$, radius başı; $O$, olekranon; $E K U$, ekstansör karpi ulnaris).

radyokapitellar eklemin 3-4 cm distalinde bulunabilir. Sinir radiusa paralel seyrettiğinden ön kolun pronasyona alınması ile sinir mediyal ve laterale doğru $1 \mathrm{~cm}$ hareket edebilir; ${ }^{[16]}$ bu sayede sinirden uzaklaşılmış olur. Ancak yine de sinir açısından dikkatli olunması gereklidir. Diğer bir dezavantajı, distale uzatıldığında yine PIS yaralanabilir. Diğer bir kısıtlaması LUKB tamiri yapmak için tüm ekstansörlerin lateral epikondildeki izometrik noktadan kesilmesinin gerekmesidir. PIS problemi nedeniyle, lateral yaklaşımlar için genellikle Kaplan yerine Kocher yaklaşımı tercih edilir. ${ }^{[2]}$

\section{Kocher lateral yaklaşım}

Ekstansör karpi ulnaris (EKU) ile ankoneus arasından girilir. Bu aralık PIS'den uzakta ve posteriorunda ve LUKB'nin anteriorunda yer alır. Lateral epikondilden, olekranon tipinin $5 \mathrm{~cm}$ distaline kadar uzanan insizyon yapılır. EKU anteriora, ankoneus posteriora ayrılır (Şekil 9). Kapsül LUKB'nin anteriorunda longitudinal olarak açılır. Radyokapitellar eklemin palpe edilmesi ve eklemin ekvator hizasının anteriorunda kalınması önemlidir (Şekil 10). Ayrıca, supinatör

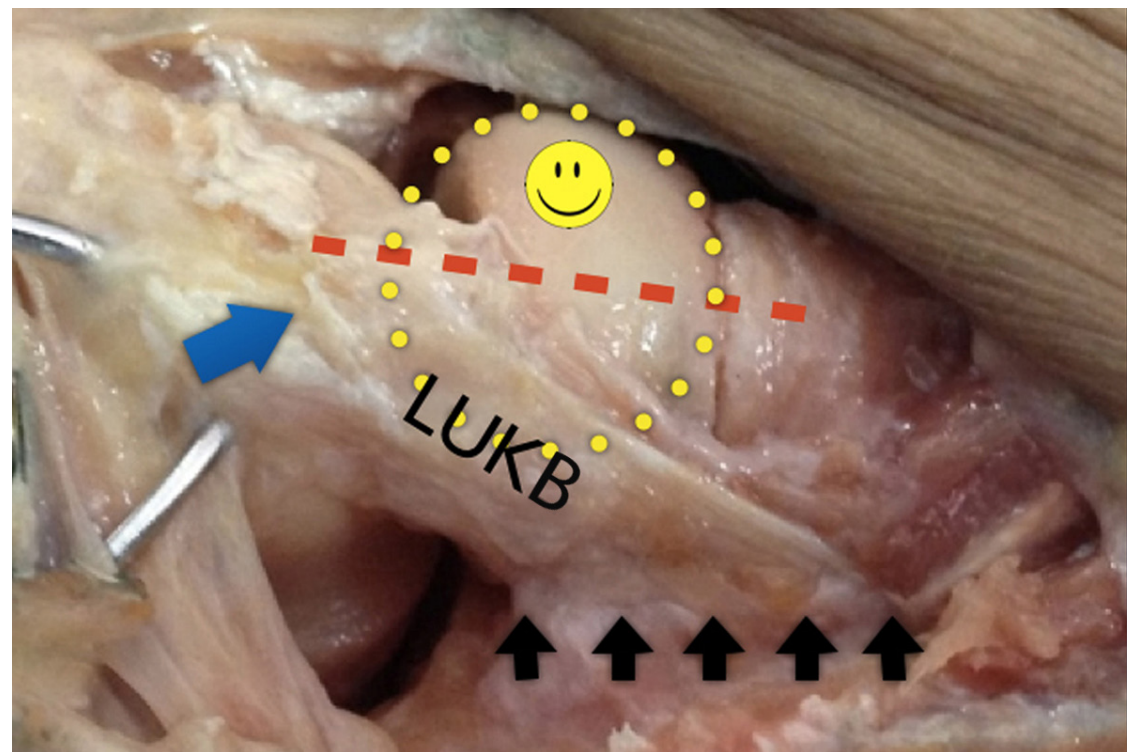

Şekil 10. Lateral yaklaşımda LUKB'ye zarar vermemek için kapsülün radius başının ekvatorunun (kırmızı kesikli çizgi) anteriorundan açılması gereklidir (LUKB, lateral ulnar kollateral bağ; içi dolu mavi ok, LUKB'nin origosu; içi dolu siyah oklar, LUKB'nin proksimal ulnadaki insersiyosu). 

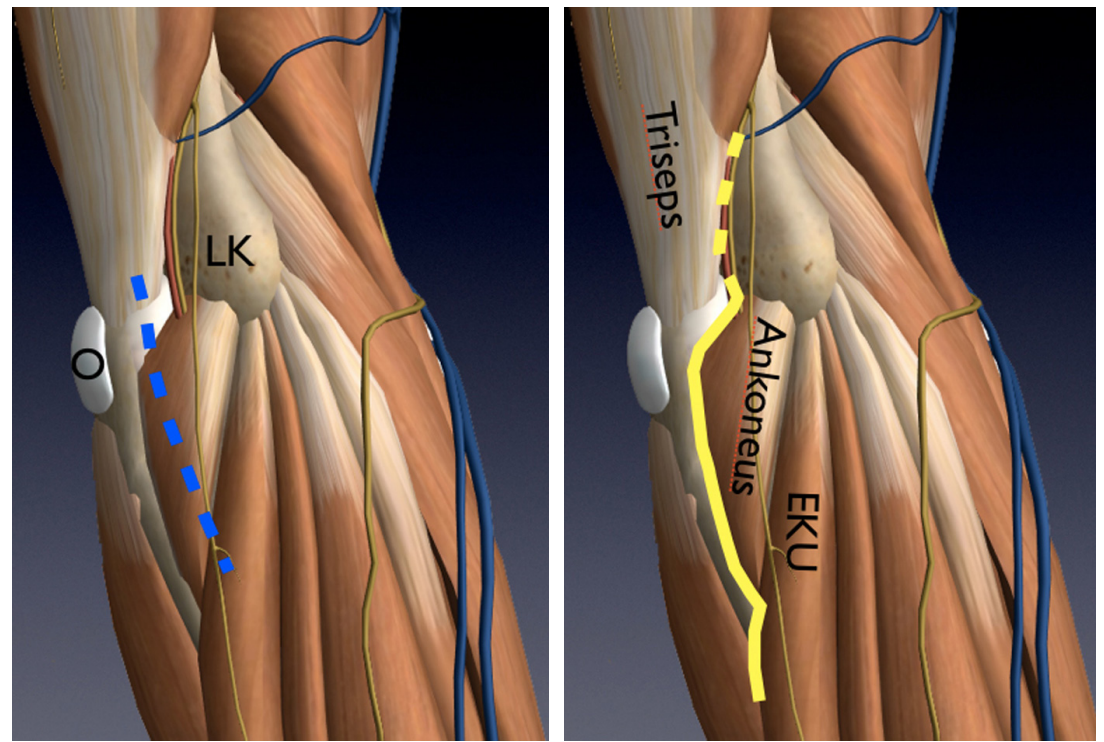

Şekil 11. Kocher uzatılmış posterolateral yaklaşım ( $L K$, lateral kondil; $E K U$, ekstansör karpi ulnaris).

kristanın anteriorunda kalındığı takdirde, anüler ligament de korunmuş olur. Kocher yaklaşımı distale ve proksimale doğru ilerletilebilir. Proksimal için, birleşik ekstansör tendonun suprakondiler bölgeden ayrılması gereklidir.

\section{Lateral kolon yaklaşımı}

Bu yaklaşım sert dirsek tedavisi için tasarlanmıştır. ${ }^{[17]}$ Anterior ve posterior kapsülün ve osteofitlerin bu yaklaşım ile eksizyonu mümkündür. Bu yaklaşım mediyal Hotchkiss yaklaşımı ile kombine edildiğinde tüm dirseğe ulaşılabilir. ${ }^{[12]}$ Kocher insizyonunun proksimal yarısı şeklinde insizyon yapılır. Brakiyoradyalis ve ekstansör karpi radyalis longus kasları lateral kolondan ayrılır. Superolateral kapsüle erişilir. Anteriorda brakiyalis adalesi distal humerus anteriorundan ve anterior kapsülden ayrılır. Kasın altına konan bir elevatör ile kas, radyal sinir, median sinir ve brakiyal arter korunmuş olur. Anterior kapsül, lateralden mediyale doğru ortaya konur. Aynı şekilde, triseps distal humerus posteriorundan ayrılarak posterior kapsül ortaya konabilir.

\section{POSTEROLATERAL YAKLAŞIMLAR}

Proksimal ulno-humeral ve radyo-humeral eklemlerin ve distal humerus posterolateralinin görüntülenmesi, Boyd posterolateral yaklaşım ile sağlanır. ${ }^{[18]}$ İnsizyon lateralde lateral kondilin posteriorundan başlar ve olekranon tipinde sona erer. Ankoneus ve EKU ulna proksimalinden subperiosteal sıyrılır. Supinatör sıyrılır, bu aşamada LUKB'nin ulna yapışma yerinin korunmasına dikkat edilmesi gereklidir (Şekil 10). Supinatör sıyrılırken radyal sinirin derin dalı korunmalıdır.

Kocher uzatılmış posterolateral yaklaşımda, insizyon suprakondiler bölgeden, kondilin hemen arkasından ankoneus kası boyunca distale doğru uzatılır (Şekil 11). Ankoneus ulnadan tamamen kaldırılır. Kapsül kesilerek ekleme ulaşılır. Bu yaklaşımın Mayo modifikasyonunda, triseps olekranondan lateralden mediyale doğru sıyrilır. Bu sayede tüm proksimal ulna ortaya konmuş olur.

\section{BÍLGi}

Şekillerin oluşturulmasında kullanılan bazı imajlar www.zygotebody.com sitesinden alınmıştır.

\section{KAYNAKLAR}

1. Cheung EV, Steinmann SP. Surgical approaches to the elbow. J Am Acad Orthop Surg 2009;17(5):325-33.

2. Morrey BF. Surgical exposures of the elbow. In: Morrey BF, Sanchez-Sotelo J, editors. The elbow and its disorders. Philadelphia: Saunders Elsevier; 2009. p.115-42.

3. Wilkinson JM, Stanley D. Posterior surgical approaches to the elbow: a comparative anatomic study. J Shoulder Elbow Surg $2001 ; 10(4): 380-2$.

4. Athwal GS, Rispoli DM, Steinmann SP. The anconeus flap transolecranon approach to the distal humerus. J Orthop Trauma 2006;20(4):282-5.

5. Coles CP, Barei DP, Nork SE, Taitsman LA, Hanel DP, Bradford Henley M. The olecranon osteotomy: a six-year experience in the treatment of intraarticular fractures of the distal humerus. J Orthop Trauma 2006;20(3):164-71. 
6. Bryan RS, Morrey BF. Extensive posterior exposure of the elbow. A triceps-sparing approach. Clin Orthop Relat Res 1982;(166):188-92.

7. Wolfe SW, Ranawat CS. The osteo-anconeus flap. An approach for total elbow arthroplasty. J Bone Joint Surg Am 1990;72(5):684-8.

8. O'Driscoll SW. The triceps-reflecting anconeus pedicle (TRAP) approach for distal humeral fractures and nonunions. Orthop Clin North Am 2000;31(1):91-101.

9. Campbell WC. Incision for exposure of the elbow joint. The American Journal of Surgery 1932;15(1):65-7.

10. Van Gorder GW. Surgical approach in supracondylar "T" fractures of the humerus requiring open reduction. J Bone Joint Surg 1940;22(2):278-92.

11. Alonso-Llames M. Bilaterotricipital approach to the elbow. Its application in the osteosynthesis of supracondylar fractures of the humerus in children. Acta Orthop Scand 1972;43(6):479-90.

12. Kasparyan NG, Hotchkiss RN. Dynamic skeletal fixation in the upper extremity. Hand Clin 1997;13(4):643-63.
13. Taylor TK, Scham SM. A posteromedial approach to the proximal end of the ulna for the internal fixation of olecranon fractures. J Trauma 1969;9(7):594-602.

14. Selesnick FH, Dolitsky B, Haskell SS. Fracture of the coronoid process requiring open reduction with internal fixation. A case report. J Bone Joint Surg Am 1984;66(8):1304-6.

15. Han SH, Yoon HK, Rhee SY, Lee JK. Anterior approach for fixation of isolated type III coronoid process fracture. Eur J Orthop Surg Traumatol 2013;23(4):395-405. CrossRef

16. Strachan JC, Ellis BW. Vulnerability of the posterior interosseous nerve during radial head resection. J Bone Joint Surg Br 1971;53(2):320-3.

17. Mansat $\mathrm{P}$, Morrey $B F$. The column procedure: a limited lateral approach for extrinsic contracture of the elbow. J Bone Joint Surg Am 1998;80(11):1603-15.

18. Boyd $H$. Surgical exposure of the ulna and proximal third of the radius through one incision. Surg Gynecol Obstet 1940;71:86-8. 